\title{
The Royal Academy Exhibition
}

$I^{\mathrm{T}}$ is always of interest to the student of natural science to see the impression which the objects of his study produce upon the artistic eye. In respect of the range of nature study at the Royal Academy there is, however, a lamentable falling off in the matter of natural history. With the exception of Mr. Peter Scott's "Barnacle Geese in April" (210) there is scarcely anything of note, and the almost total absence of studies of big game, notably of the great carnivora, is very disappointing. Yet the material is not lacking, for there is a remarkably fine exhibition of contemporary big game pictures in a neighbouring gallery, not "mere transcripts of the objects of Natural History" but true artistic compositions.

Landscape, however, continues to be well represented. There is a large number of pleasing pictures of English scenes in which architecture provides the focal feature amidst natural surroundings. In the verdant landscape of the English plain a village church or a distant cathedral provides the artist with the massive and formal element which is lacking in a country from which the harder rocks are absent. Again, in the hilly landscapes we find studies such as that by $\mathrm{Mr}$. Stanley Royle of "Mont Orgueil Castle, Jersey" (265), in which an architectural feature crowning an eminence develops the rocky forms to a pitch of steepness and a regularity of symmetry towards which Nature seems to strive but never quite attains. Such examples of artistic treatment provide a valuable lesson for the scientific observer, for the artistic outlook is more in accordance with the natural faculties of the eye than that which results from classifying objects by their physical qualities.

Among the most pleasing illustrations of the combination of architectural and natural features are those of bridges, with massive piers and arches spanning smoothly flowing water. In "A Welsh Bridge" (189) by Mr. Oliver Hall, the combination is enhanced by a rocky background which harmonises with the massive masonry. This picture brings home very forcibly the need for scheduling such structures as ancient monuments for preservation, a lesson emphasised by Mr. Charles Cundall's beautiful picture of a sad event, "The Demolition of Waterloo Bridge" (447).

In the illustration of the seasons, the Academy will greatly miss the late Mr. J. Farquharson's snow studies, of which, however, the present exhibition contains one small example, "In Glen Garry" (558).

In natural scenery the mode of illumination is scarcely less important than the features themselves, and we are indebted to Mr. J. Olsson for his beautiful study of moonlight-"Moonlit Surf : Irish Coast" (297). There is also one very fine study made in the deepening darkness of the night, "Santa Maria della Salute, Venice" (532), the diploma work of Mr. Richard Sickert.

Mr. A. E. Kelly's "Mount Sefton, New Zealand" (669) is one of the few pictures of the scenery of distant lands. The want of studies of tropical scenery will be particularly felt by those who can recall the magnificent sunset effects in the equatorial belt.

Among the portraits are several of personal interest to the scientific community. Mr. Francis Dodd's "The Lord Rutherford of Nelson, O.M." (1207) is a strong drawing of a strong face. Mrs. Dodgson's drawing of the late Prof. $H$. $H$. Turner (1253) renders admirably the quiet humour of the eyes beneath a thoughtful brow. Mr. Augustus John has portraits of Lord Conway of Allington (284) and Prof. J. C. McLennan (288). Mr. George Harcourt gives us a portrait of Colonel R. E. B. Crompton (368) which reveals a vigorous personality, and in Sir James Crichton-Browne by Mr. Oswald Birley (314) we see a fine rendering of calm and thoughtful reminiscence.

Vaughan Cornish.

\section{The Royal Jubilee}

\section{Addresses from the Royal Societies of London and Edinburgh}

$\mathrm{I}^{\mathrm{N}}$ addition to the messages of devotion and loyalty sent to the King from civic and governing authorities of the Empire at home and overseas, expressing congratulations to His Majesty upon the celebration of the silver jubilee of his accession, addresses were presented by a number of representative scientific societies. The addresses submitted by the Royal Societies of London and Edinburgh are reprinted below.

To the King's Most Excellent Majesty

May it please Your Majesty,

We, Your loyal and dutiful subjects, the President, Council and Fellows of the Royal Society, humbly 